\title{
STUDENT PROJECT: INTERPRETING TARGET 8 OF THE GLOBAL STRATEGY FOR PLANT CONSERVATION: A CASE STUDY OF INTERPRETATION PANELS AT A RANGE OF GARDENS IN BRITAIN
}

\author{
Katarzyna Goral ${ }^{1}$
}

\begin{abstract}
This article examines how interpretation panels communicate plant conservation to garden visitors. The focus of the study is on interpretation themes and stories, messages conveyed, and textual and visual devices used. Special attention is paid to how the information on Target 8 of the Global Strategy for Plant Conservation is presented. The case study focused on interpretation panels at the Royal Botanic Garden Edinburgh (RBGE) and its three Regional Gardens. An assessment of the display panels at RBGE was carried out for visitor opinion and perception and these were replicated and compared with similar panels in three other gardens in the UK. The results of these assessments and a brief study of visitor behaviour contributed to a set of suggestions for future interpretation provided here. This article is an extract from the author's HND Specialist Project written for the RBGE Diploma in Horticulture with Plantsmanship in June 2013.
\end{abstract}

\section{INTRODUCTION}

Interpretation of plant conservation in public gardens can be challenging. The main problem is that there is little interest displayed by garden visitors in educational activities such as reading about conservation issues. Studies by Connell (2004) and Waterson \& Saunders (2012) show that restoration, leisure and socialising are far more common motivations for garden visits than learning and discovery. Another significant challenge is low interest and commitment to conservation issues displayed by visitors to gardens. A study by Ballantyne, Packer \& Hughes (2008) revealed this lack of interest amongst visitors to Mt Coot-tha Botanic Gardens in Brisbane, Australia.

As many public gardens are increasing their plant conservation efforts it is becoming more important to find new ways of communicating conservation messages and issues to the public. This article, which is an extract from the author's HND Specialist Project, evaluates conservation messaging through examples of environmental interpretation from the Royal Botanic Garden Edinburgh (RBGE) and its Regional Gardens. RBGE was selected for this case study because of its strong commitment to the conservation of local flora within the Scottish Plants Project. Through this initiative RBGE joins in the worldwide programme of conserving flora - the Global Strategy for Plant Conservation (GSPC).

\footnotetext{
1. Katarzyna Goral graduated from the HND in Horticulture with Plantsmanship at the Royal Botanic Garden Edinburgh in 2014.

Address: 0/1, 48 Maxwell Drive, Glasgow G41 5JT.

Email: ek.goral@gmail.com
} 
This project looks specifically at interpretation panels and examines the communication of RBGE's commitment to Target 8 of the GSPC. This target calls for the safeguarding of threatened flora in ex situ collections - a task which RBGE has supported for many years (McHaffie, 2011; RBGE, 2013). Apart from evaluating existing panels, this article also makes suggestions for future interpretation. The inspiration for this research was the construction of a new display at RBGE dedicated to growing Scottish native flora with a selection of threatened species. Once planted up, and with interpretation panels installed, this bed is expected to become a showcase for RBGE's work on plant conservation and its involvement in the GSPC.

\section{BACKGROUND INFORMATION}

Environmental interpretation: definition and key elements

In the second half of the 20th century there have been many attempts to define the concept of environmental interpretation. Some scholars view it as a public service (Tilden, 1977) or assistance to visitors (Sharp, 1976) while others regard it as a form of communication (Ham, 1992). The function of interpretation is twofold: it should be an educational activity with a strong focus on entertainment. In literature a range of verbs is used to denote the educational component, from 'explain' or 'translate' (Ham, 1992) to 'reveal' (Tilden, 1977) and 'develop awareness and appreciation' (Sharp, 1976). The entertainment component is simply expressed as 'making the visit a rich and enjoyable experience' (Sharp, 1976).

To develop interesting and meaningful interpretation, it is necessary to consider its three key elements: the resource, the visitor and the interpretative medium (Sharp, 1967). The resource is the 'thing' itself - a place, a piece of the natural world, an artefact or a concept which is being explained and revealed through interpretation (Sharp, 1967). To hold visitor attention the resource should be presented in a way that is entertaining (Ham, 1992). As Tilden says, interpretation needs to tell a story (1977).

A story is any presentation conveyed by talking, writing or other means that has a beginning and an end, message or moral (Ham, 1992). The glue that holds the story together is the theme - 'the main point or message the communicator is trying to convey' (Ham, 1992).

Visitors play an important part in the interpretation planning process as they often dictate the choice of medium, style of interpretation, structure and usage of visual and textual devices. To understand visitor needs and wants, many studies have been conducted in recent years. Researchers looked into motivations for the visit (Ballantyne et al., 2008; Connell, 2004; Waterson \& Saunders, 2012) and demographics (age, social status, frequency of visits). Studies on visitor behaviour led to developing a typology of streaker, stroller and studier based on differences in the pace and attention paid to both exhibits and interpretation (Legrand, 2005). This provided guidelines on structuring 
the interpretation to reach all three visitor types (Monroe et al., 2006). ${ }^{2}$ Although this typology has been developed based on studies of visits to museums, it has also been applied by interpreters of gardens, for example at the University of Bristol Botanic Garden (UBBG) (Wray, 2013, pers. comm.).

Finally, the last piece of the interpretation puzzle is the medium. There is a wide variety of media in use from static forms (panels, boards, leaflets, maps, audioguides and exhibitions) to live forms such as guided walks, talks, drop-in sessions, workshops and events. As Sharp (1967) notices, the choice of medium depends on the visitor (for example, adult or child) and the resources available (such as staff levels, funding and maintenance issues).

\section{TARGET 8 OF THE GLOBAL STRATEGY FOR PLANT CONSERVATION}

Is it important to communicate the GSPC to visitors in gardens? The GSPC was proposed by the United Nations Convention on Biological Diversity and the overarching purpose was to halt extinction of plant species across the world (CBD, 2012a). It provides a holistic framework for the conservation of flora at local, national and global level by coupling research into and documentation of plant diversity with in situ and ex situ conservation of threatened plants and habitats, promoting and supporting sustainable use of the world's plant resources and raising awareness of the importance of plant diversity for the livelihood of humans (Plants2020, n.d.). This framework is expressed through 16 outcome-oriented targets providing guidance for developing national plant conservation targets (BGCI, 2012).

The GSPC was first proposed in 1999 and was adopted by the world's governments in 2002 (CBD, 2012b). Since then many initiatives have been stimulated across the world, leading to greater collaboration and the establishment of nationwide programmes (Sharrock et al., 2010). An example of such an initiative in the UK is the PlantNetwork Target 8 Project, developed in response to Target 8 of the GSPC (PlantNetwork, 2013).

This particular target calls for safeguarding at least 75 per cent of threatened flora in ex situ collections - 20 per cent of threatened species are to be available for restoration and recovery programmes (Plants2020, n.d.). To make this target achievable, PlantNetwork proposed to spread the conservation effort among UK botanic gardens, arboreta and other documented plant collections. The idea was simple - each garden member was to grow two to three locally occurring but nationally threatened species, leading to the creation of a nationwide ex situ living collection of Britain's threatened flora (Frachon et al., 2005).

Another goal of the project is to increase horticultural expertise and knowledge on propagation and cultivation of Britain's native plants with the aim of creating a collective database of germination and cultivation protocols in the future (PlantNetwork, 2013).

2. Designing with all three behaviours in mind leads to multi-layered interpretation with a high-priority message presented in the title and less-prioritised information supplied lower in the text body. 


\section{TARGET 8 AT THE ROYAL BOTANIC GARDEN EDINBURGH}

RBGE is a member of PlantNetwork (the plant collections network of Britain and Ireland) and for many years the staff have been involved in the collection and cultivation of Scotland's rare and threatened species as a part of the Scottish Plants Project. ${ }^{3}$ The project started in 1991 as a partnership between the Nature Conservancy Council and RBGE (RBGE, 2013a). Originally its focus was the survey and monitoring of populations of threatened species and ecological research. Around four to six years from its launch the scope of the project was extended into habitat management, ex situ conservation and restoration programmes (Lusby, 2013, pers. comm.).

To date 143 of Scotland's rare and threatened plants have been propagated and cultivated in the RBGE nursery with many stored as seeds (McHaffie, 2013). Around eight or nine species were selected and used for reintroduction programmes including the fern Woodsia ilvensis, three species of mountain willow (Salix lanata, S. lapponum and S. myrsinifolia) and the herbs Ajuga pyramidalis, Polygonatum verticillatum, Crepis mollis and Lychnis viscaria (McHaffie, 2011). The Garden also holds a collection of Sorbus species endemic to the Isle of Arran (S. arranensis, S. pseudofennica and $S$. pseudomeinichii) with the intention of using them for future reintroduction projects (McHaffie et al., 2011).

RBGE increases horticultural knowledge of the cultivation of Scottish threatened species by collecting information on seed germination, plant growth and cultivation procedures (McHaffie, 2013). Some attention has been devoted to horticultural trials, such as the droughting experiment on Woodsia ilvensis (McHaffie, 2006).

\section{METHODOLOGY}

Research for this project was conducted by using a range of techniques. A starting point was an overview of Target 8-related interpretation ${ }^{4}$ at all of RBGE's Gardens (i.e. at Edinburgh, Dawyck, Logan and Benmore) to get a comprehensive assessment of RBGE's interpretation strategy on conservation of the Scottish flora. This involved a visual assessment of the information panels, boards, maps, leaflets and exhibits found across the four Gardens. Information on live interpretation was also collected by searching current and past issues of RBGE's publications What's on at the Botanics and the Botanics magazine and interviews with Head of Events at RBGE Ian Edwards and Heather McHaffie. A series of interpretation panels was selected for a visitor opinion survey. This was conducted at Dawyck Botanic Garden using a questionnaire (see Appendix 1).

At the same time a temporary panel was produced and fitted for installation within the new Scottish Plants Bed at RBGE in Edinburgh. This panel, designed solely for this

3. Information on the Scottish Plants Project was obtained from personal interviews with Phil Lusby and Heather McHaffie, former and present Scottish Plant Officer at RBGE, journal articles and presentations by H. McHaffie and N. Frachon listed in the Reference section and RBGE website.

4. Target 8-related interpretation at RBGE is understood in this work as interpretation on the topic of conservation of Scotland's rare and threatened species within the Scottish Plants Project headed by Heather McHaffie. 
project, served as a base for the second visitor opinion and behaviour survey conducted at Edinburgh.

Finally, panels at RBGE were compared with conservation panels of local flora at three other Gardens across the UK.

All background information was obtained from published literature, electronic sources and personal interviews with RBGE staff involved in the conservation of Scottish flora (Heather McHaffie, Phil Lusby, Natacha Frachon and Kate Barnard) and the RBGE interpretation team (Alan Bennell and Vlasta Jamnický).

\section{FINDINGS}

\section{RBGE interpretation strategy on conservation of Scottish flora}

In the late 1990s, RBGE initiated a project to revamp its displays and interpretation of Scottish flora across all four Gardens. The task of developing landscape designs and an interpretation strategy was assigned to John Finlay Associates, who developed a proposal for four new displays of Scottish flora united under one interpretation theme (John Finlay Associates, 1998). Today, only two of the proposed displays remain: the 'Local Heroes' bed at Logan and the 'Scottish Rare Plants Trail' at Dawyck. Both displays contain species on the Target 8 list for Scotland, ${ }^{5}$ two examples of which are Woodsia ilvensis and Lychnis viscaria. In June 2013, when this project was submitted to RBGE's Education Department, panels accompanying these displays were the main source of RBGE interpretation on the conservation of Scottish flora available to the general public across the four Gardens.

Other panels, boards and exhibits interpreting the conservation of Scottish plants are dispersed throughout RBGE Gardens and are not linked with each other. Live interpretation on the topic is in the form of drop-in sessions and guided walks by Heather McHaffie. These events are not very frequent or are restricted to specific groups of visitors so they can only reach a limited audience. ${ }^{6}$

\section{TARGET 8-RELATED INTERPRETATION PANELS AT DAWYCK AND LOGAN}

How do the panels at Logan and Dawyck convey the conservation message? They do so in two different ways. The main information board situated at the start of the trail (Dawyck) and in the centre of the bed (Logan) informs visitors in simple terms about the decline of native species and the role of RBGE in conserving them. Both boards omit any mention of the GSPC or Target 8, but contain brief information about the Scottish

5. The Target 8 list for Scotland can be viewed at http://rbg-web2.rbge.org.uk/scotplant/Target\%208/The\%20List.html. 6. A search through current and past issues of RBGE's events directory What's on at the Botanics shows the drop-in sessions have been taking place at approximately six-month intervals or in some years even less frequently. Heather McHaffie also leads guided walks on the topic of Scottish threatened plants. These, however, are addressed to specific groups of visitors such as members of RBGE, the Alpine Garden Club, the British Pteridological Society, etc., rather than the general public (McHaffie, 2013, pers. comm.). 
Plants Project. They also appeal to national sentiments referring to the Scottish flora as an important component of the nation's natural heritage.

The boards are accompanied by a series of smaller panels, each of them presenting one rare/threatened species. Their content ranges from information on distribution, growing conditions and habitats to interesting facts on biology, uses, naming and history. The panels send a strong message about the decline of featured plants, highlighting the main threats to their existence. Their purpose is to raise the profile of the Scottish flora, stimulate visitors' interest and appreciation of native species and promote awareness of their decline ${ }^{7}$ - all this without directly speaking of conservation.

The theme uniting both displays - 'Wonder at your feet' - has a similar function. It points to the small scale and fragile beauty of the plant exhibits, of which most are small herbaceous perennials. It emphasises their uniqueness and aims to increase appreciation of the 'locals' (meaning local and native plants). Graphically the theme is represented by an image of a magnifying glass.

To draw attention and appeal to a wide audience (anyone visiting the Garden, from children to adults, locals to tourists ${ }^{8}$ ) the panels are textually engaging and avoid the use of scientific terms. Their language is informal, direct, rich and colourful, with phrases such as 'eke out an existence', 'hungry mouths of sheep and goats' and catchy titles such as 'Love drug', 'Strictly vegetarian'.

The layout of the panels is playful too. At Dawyck their round shape imitates a view through a magnifying glass, strengthening the message of the plants being small and delicate and therefore needing care and attention. The panels are fixed onto nearby rocks giving an impression of blending in with the surroundings (Fig. 1).

At Logan the shape of the panels (wavy line top and bottom) together with ropes and a boat situated within the bed make a reference to the coastal distribution of presented plants ${ }^{9}$ (Fig. 2).

A visitor survey was conducted at Dawyck Botanic Garden in early spring 2013 to evaluate how RBGE's visitors notice the panels, their perception and the take-home message.

\section{VISITOR SURVEY ON THE SCOTTISH RARE PLANTS TRAIL AT DAWYCK}

Plants displayed within the Scottish Rare Plants Trail are dispersed throughout the Garden and their location is designated by the interpretation panels and a map available

7. Graham Stewart, Curator at Dawyck Botanic Garden, during an interview in March 2013 considered that the main function of the interpretation panels along the Scottish Rare Plants Trail was to raise the profile of native plants and make people aware of their decline (Stewart, 2013, pers. comm.). According to Richard Baines, Logan's Curator, the function of the panels in the Local Heroes bed is also to encourage visitors to watch out for the 'heroes' when walking in the countryside and sends a strong message that some species found locally are threatened (Baines, 2013, pers. comm.).

8. According to Richard Baines, interpretation panels in the Local Heroes bed are targeted at the widest possible audience

(Baines, 2013, pers. comm.). Phil Lusby, former Scottish Plants Project Officer at RBGE, described the target audience of the Scottish Rare Plants Trail as the general public and family groups (Lusby, 2013, pers. comm.).

9. Plants featured in the Local Heroes bed grow in coastal areas of Dumfries and Galloway at the edge of their geographical distribution, taking advantage of special climatic conditions created by the influence of the Gulf Stream and land topography (Bennell et al., 2003). 


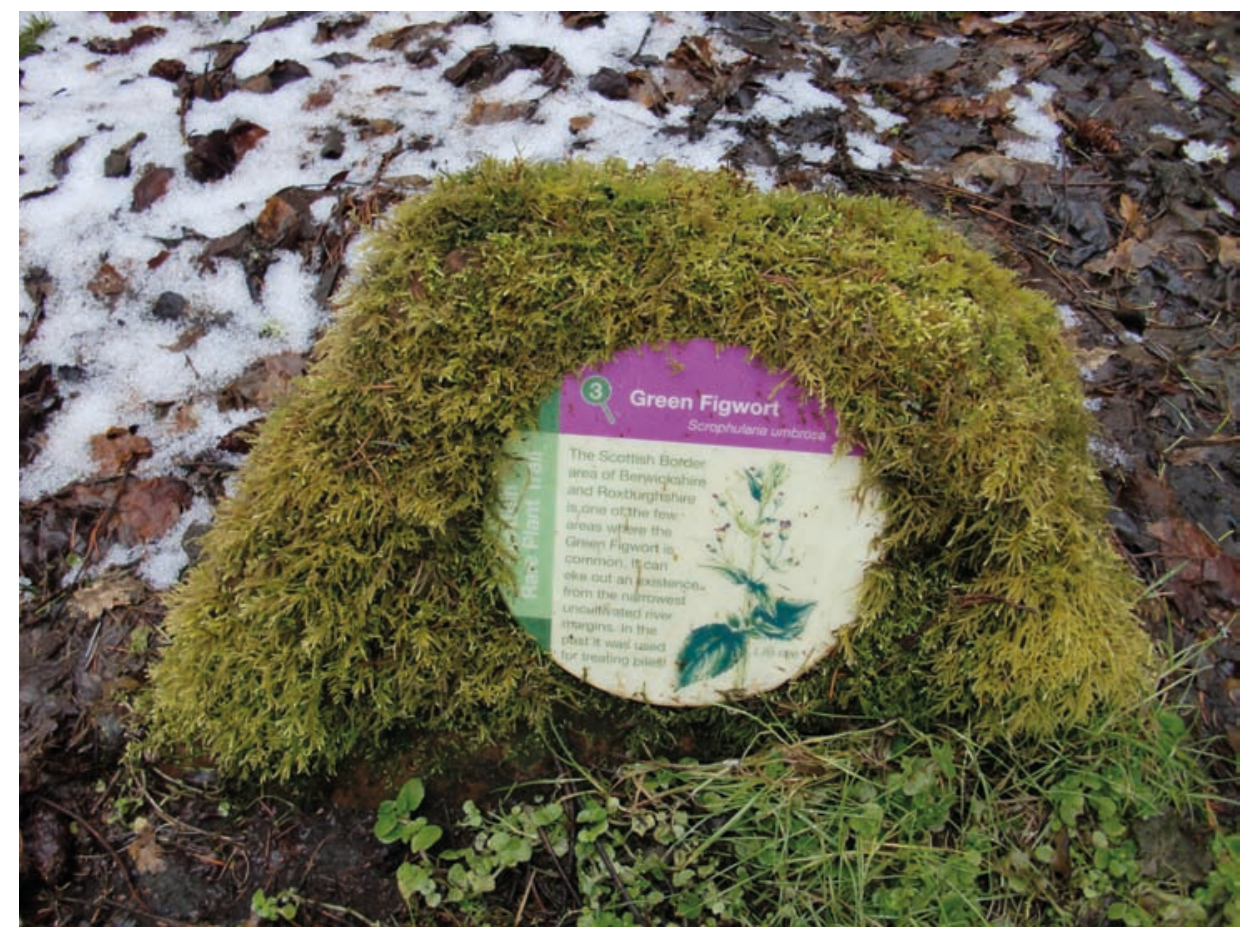

Fig. 1 Examples of interpretation panels along the Scottish Rare Plants Trail at Dawyck. Photo: Katarzyna Goral.

from the Visitor Centre. One of the goals of the survey was to evaluate the 'visibility' of the panels and determine how they contribute to the 'visibility' of the trail. The survey was conducted using a questionnaire (Appendix 1). Four out of eleven questions concerned the issue of visibility. The results showed that over 83 per cent of respondents noticed the trail, with 53 per cent reporting the panels as the main indicator drawing their attention.

Because the panels are dispersed throughout the Garden, some in more prominent position than others, the correlation between the visibility of panels and their placement was examined. Over 65 per cent of respondents noticed a panel located near the entrance to the Garden on a path leading to the Visitor Centre (see the map in Appendix 2 for No. 1), while 28 per cent remembered a panel situated along the path on the opposite side of the garden towards its north border (No. 7 on the map in Appendix 2).

Another goal was to assess the message(s) that visitors took from the panels. When asked 'what is the main message of panel 1?' (its text was quoted in the questionnaire see Q5 in Appendix 1), nearly half of the respondents pointed at the information about the rarity of the featured plant and it being a treasured member of the Scottish native flora. Approximately 30 per cent of respondents thought the factual data about the plant's growing requirements was the main message, while only 16 per cent considered 

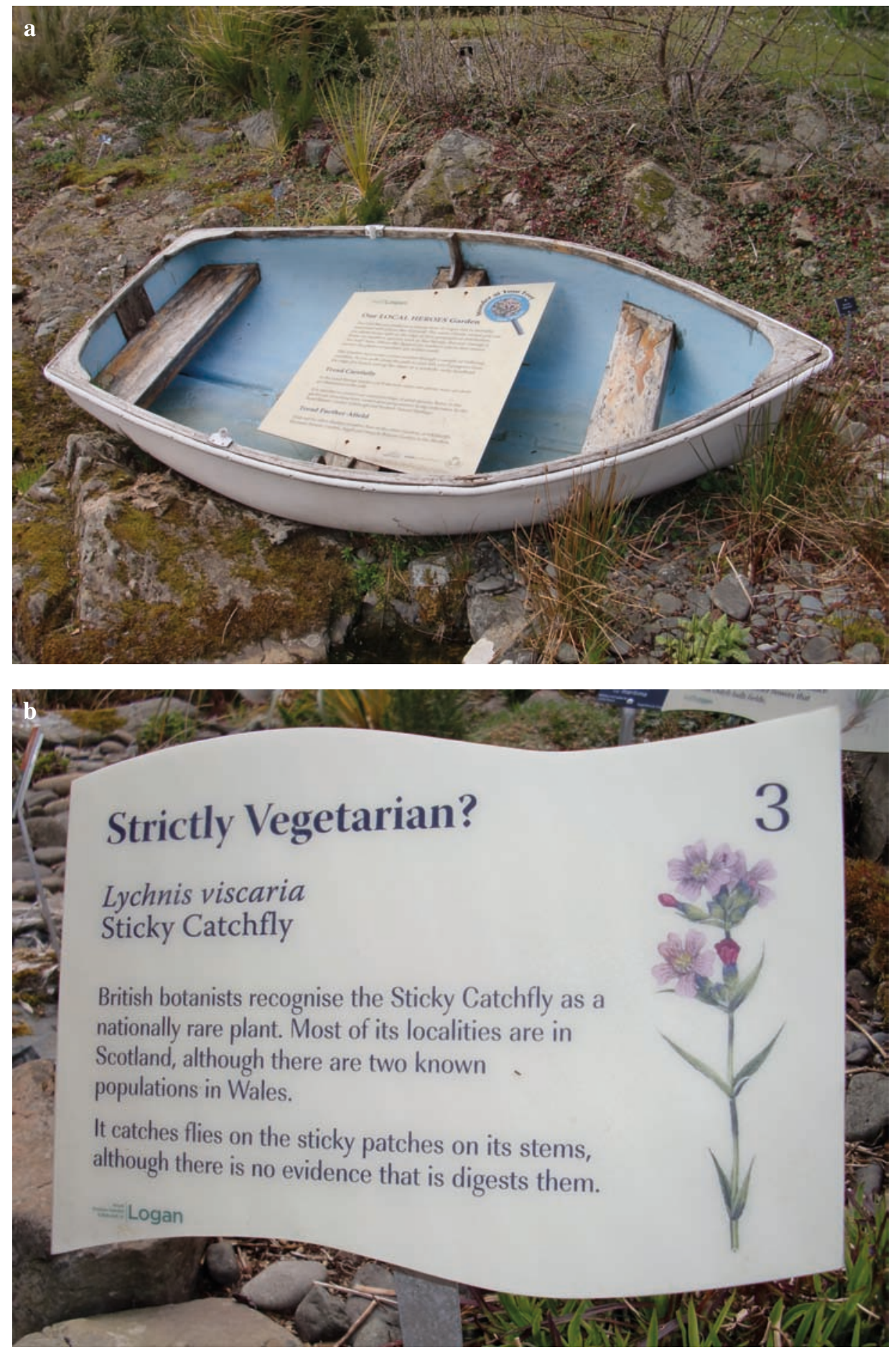

Fig. 2 Panels in the Local Heroes bed at Logan: (a) a section of the bed, (b) a close up of one of the panels. Photo: Katarzyna Goral. 


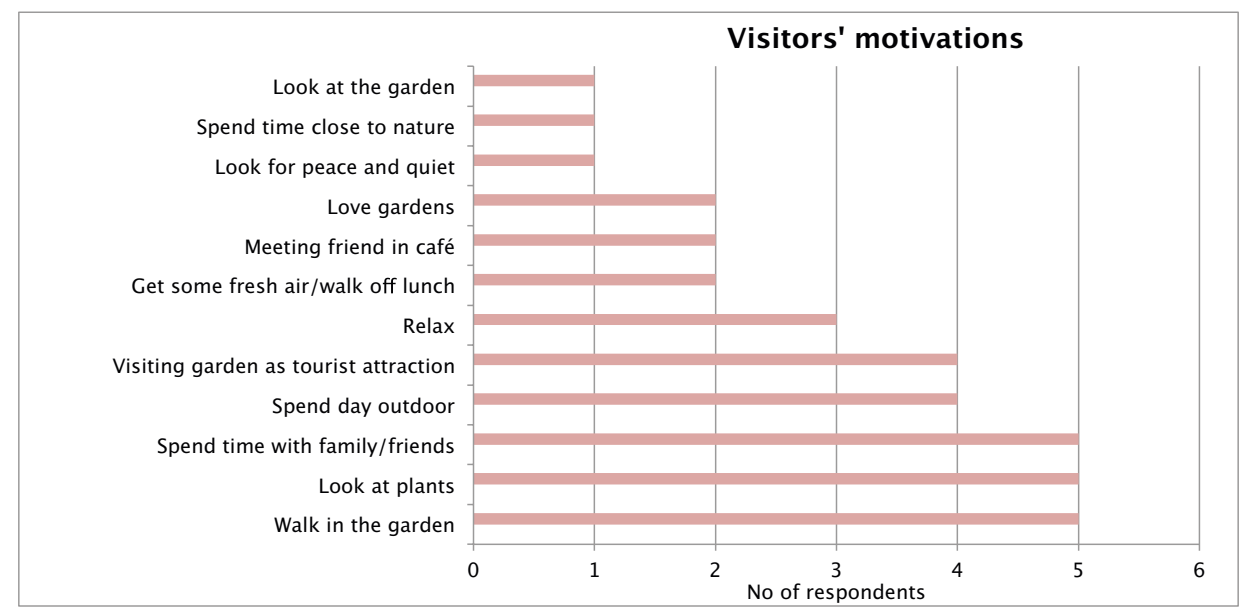

Fig. 3 Respondents' main motivations for visiting Dawyck Botanic Garden. Graph: Katarzyna Goral.

it to be about its decline due to human activity. This result shows that most visitors pointed at an answer which reflects the main goal of the interpretation - raising appreciation for Scottish rare species.

The survey also tried to evaluate visitor opinions on the language used in the panels, their layout and visual presentation. Most respondents (over 83 per cent) considered it interesting and around 32 per cent entertaining. Only 6 per cent were dissatisfied with text quality. The question on visual presentation of the panels brought interesting results with many respondents (19 out of 49) leaving it unanswered and some commenting on the placement of the panels, their size and maintenance issues. Sixteen visitors expressed a positive opinion on the visual presentation calling it attractive, eye-catching, clear and pleasant. Only five respondents expressed dissatisfaction (a full list of comments is given in Appendix 3).

Finally, when asked about the main reason for their visit, respondents indicated an array of answers (Fig. 3).

To gather data about visitor behaviour another survey was carried out at the RBGE garden in Edinburgh.

\section{VISITOR SURVEY ON THE TEMPORARY INTERPRETATION PANEL IN THE SCOTTISH PLANT BED AT RBGE}

The survey was conducted using a panel designed by the author for this purpose ${ }^{10}$ and fitted within the Scottish Plants Bed at RBGE (Fig. 4). Since the bed was under development with no plants at the time of the survey, the panel gave information on

10. The text and images were proposed by the author to best fit the purpose of the survey, while the RBGE Interpretation Team took care of the overall design and artwork to conform to RBGE's house style. 


\section{COMING SOON...}

\section{NATIVE SCOTTISH PLANTS}

The area in front of you will soon hold an exciting selection of Scottish native plants, including some of our most threatened species. They will be landscaped to reflect their natural communities and habitats as found across Scotland, from the sea shores to the mountain tops.

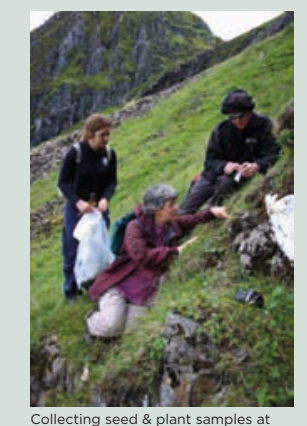

Conserving Scottish flora To halt the decline of Scottish native plants, RBGE participates in a world-wide initiative called the Global Strategy for Plant Conservation. We monitor wild populations, collect seeds and cuttings of threatened species and grow them in our Garden. Where possible, we try to reintroduce them into their natural habitats. Above all we gather knowledge and experience to understand better their growing and propagation requirements.
Habitat decline

Like humans, plants live in communities. Together they occupy habitats - areas with specific type of climate, terrain underlying rock and soil. Many of Scotland's natural habitats are affected by agriculture and climate change, reducing the number of suitable places for some plants to grow. As a result, these species become less frequent and this decline may lead to problems in the future; every plant plays a specific role in its broader habitats and such losses may undermine their stability.

Norwegian mugwort Norwegian mugwort
(Artemisia norvegic
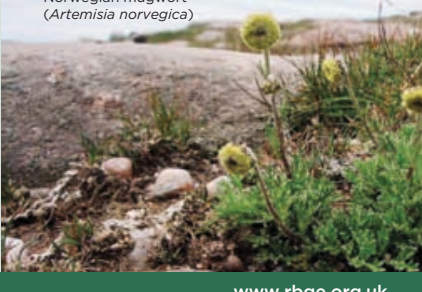

Fig. 4 A copy of the temporary interpretation panel fitted in the Scottish Plants Bed at RBGE in March 2013. Design: Vlasta Jamnický.

future plantings. This was provided in the first paragraph and the title which gave an instant message on what plants were to come. The panel was written avoiding scientific terminology and using direct language and simple comparisons when explaining more complex ideas.

One of the goals of the survey was to measure how effective the panel was in attracting visitors' attention. Counting the number of visitors passing by the panel and noting down how many of them glanced at it or stopped to read it gave the following results: out of 480 passers-by 83 glanced at the panel without stopping and 44 (less than 10 per cent!) stopped to read it. The panel attracted significantly more attention from adults than children. The survey mapped visitor behaviour by measuring the time spent on glancing/reading and determining which part of the panel visitors looked at. The results showed visitors had spent on average 1.51 seconds glancing at the panel and 16.67 seconds reading it. What information did visitors absorb in this short time?

The results of questioning a sample of 25 visitors who glanced at the panel showed that most of them (13 respondents) took no notice of it (common responses: 'I didn't see/ notice'; 'I have no idea'). Ten respondents thought the panel was about Scottish plants coming soon, while one noticed the information on bed layout. None of the 25 glancing respondents picked up the information on conservation. 
Questioning a sample of 25 visitors who read the panel showed that all respondents picked up the information about Scottish natives coming soon with eight mentioning planting of threatened species. In summary, most respondents looked only at the title, first paragraph and photograph, skipping the rest of the text.

The same sample of 25 visitors who stopped to read the panel were also questioned about opinions on text quality, visual presentation of the panel and motivations for their visit. In general, respondents were satisfied with both text and visuals. Respondents displayed a wide range of motivations with social and restoration being the main two.

To find out how other gardens communicate about conservation of native flora using interpretation panels and compare them with panels at RBGE a series of visits to other UK gardens was undertaken in spring 2013.

\section{INTERPRETATION OF NATIVE FLORA IN OTHER GARDENS}

Gardens selected for the study were: University of Bristol Botanic Garden (UBBG), Bristol Zoo Garden and University of Dundee Botanic Garden (UDBG). The main selection criterion was whether the garden was involved in the PlantNetwork Target 8 Project and had a display collection of Target 8 plants.

During these visits attention was paid to:

- stories and themes

- the message communicated

- the audience targeted

- the method of reaching the audience, i.e. style of language, layout, graphics.

In all three gardens interpretation panels aimed to raise the profile of local flora by emphasising its uniqueness and presenting the local area as a biodiversity hotspot. To reach this goal the panels used a variety of stories. At UBBG one of them is the story of the whitebeam family in Avon Gorge. It explains in detail the hybridisation processes leading to the development of Sorbus spp. diversity in the Gorge. The emphasis is placed on the great number of Sorbus species found locally, of which many are endemic to the Gorge.

At Bristol Zoo one of the stories takes the audience back 200 years to look at the Avon Gorge, a biodiversity hotspot, when it was grazed by sheep. The story stresses the decline of plant diversity throughout the years caused by change in land management, invasion of garden escapees or deliberate introduction of non-local species.

An example from UDBG is the story of Astragalus alpinus, a rare species with adaptation to permanent snow cover in winter. The panel emphasises that the existence of the species in Scotland may become threatened because of climate change.

The gardens differed in the style they chose to reach their visitors - this is directly linked to the audience they target. At UBBG the panels were text heavy with lots of factual data presented in a style using factual language and scientific terms, e.g. polyploidy, apomixis. The information was multi-layered, with titles highlighting the 


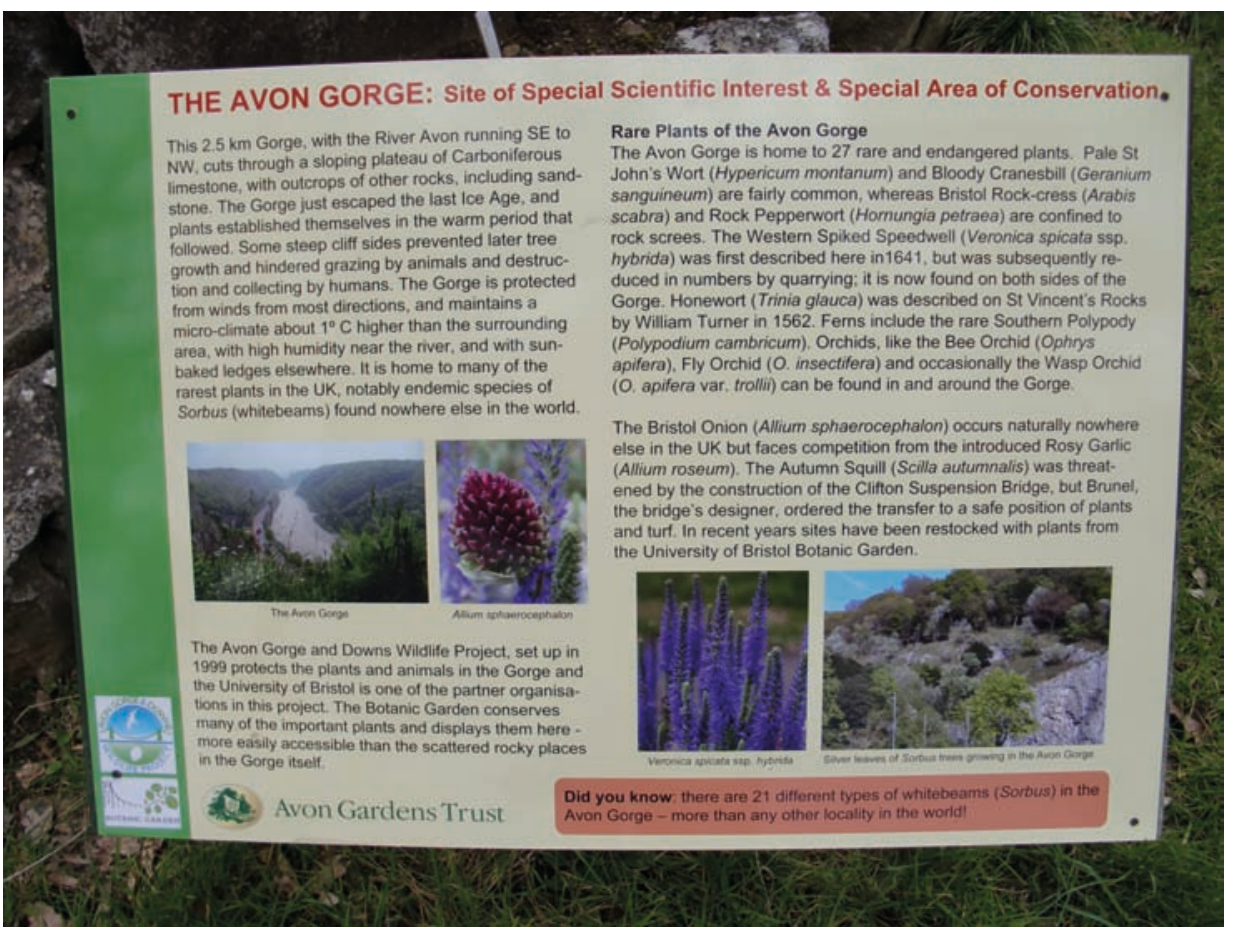

Fig. 5 An example of an interpretation panel from the University of Bristol Botanic Garden. Photo: Katarzyna Goral.

subject matter, photographs drawing attention to and supporting the text, and a 'Did you know' box at the bottom. Such a layout was intended to attract three different categories of target audience: the streaker, the stroller and the studier. ${ }^{11}$ The visuals included photographs, maps and drawings. The layout was simple - black text against a white background, matching the matter-of-fact style of writing (Fig. 5).

At Bristol Zoo the panels were about fun and attraction. They tried to attract the attention of a young audience and family groups by playing a lot with visuals and language. A satellite map, enlarged or off-focus photographs and paintings were used as backgrounds for the text. Smaller images were round and often overlapping - bubblelike snapshots of flower heads, butterflies, birds and so on (Fig. 6).

To dramatise the conservation message the panels used phrases such as 'meadows like this almost disappeared from British countryside' and 'top 5 natural sites in UK'. The language was direct, colourful and at times poetic with expressions like 'meadow magic' and 'swaying grasses studded with orchids'. At UDBG the panels had a strong guiding function directing and encouraging visitors to follow the path into subsequent vegetation zones. To draw the visitors' attention they used catchy titles such as

11. The information on target audience and strategy to reach streaker-stroller-studier was provided by Nick Wray, Garden Curator, during a personal interview on 27 March 2013. 


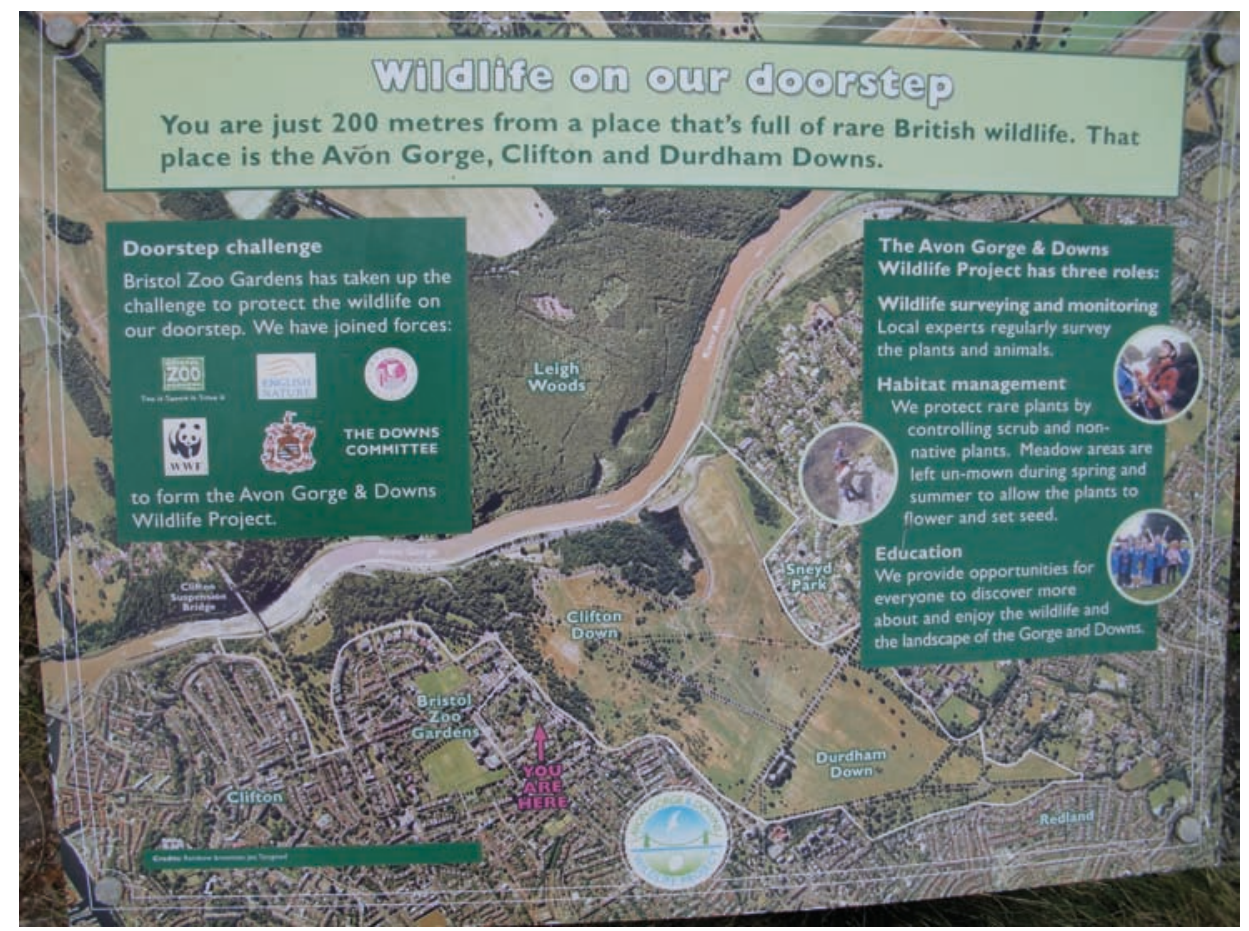

Fig. 6 An example of an interpretation panel from Bristol Zoo. Photo: Katarzyna Goral.

'Warming to Extinction' or 'Welcome to the Wild'. Part of the interpretation was an interactive calendar - a horizontal tube with a knob on one side (Fig. 7). Turning the knob took the visitor from month to month and provided information about changes to local flora and wildlife activity.

\section{CONCLUSIONS AND RECOMMENDATIONS}

The survey conducted at Edinburgh showed that visitors pay little attention to interpretation panels (less than 10 per cent of passers-by stopped to read the surveyed panel). Visitors also spend little time reading (on average 16.67 seconds) and rarely looked beyond the title and first paragraph. The survey at Dawyck demonstrated that for many visitors the panels were the main pointers drawing their attention to plant displays. Their positioning within the garden has, however, a crucial impact on their visibility which can drop significantly (by more than half) if a panel is placed in a less prominent location. Both surveys showed that visitors came to gardens for a variety of reasons but when asked to choose their main motivation, most pointed to leisure and spending time with friends and family, not education or finding out about conservation.

The assessment of interpretation panels at RBGE and other gardens demonstrated that there is a range of textual and visual devices in use to attract visitors' attention and 


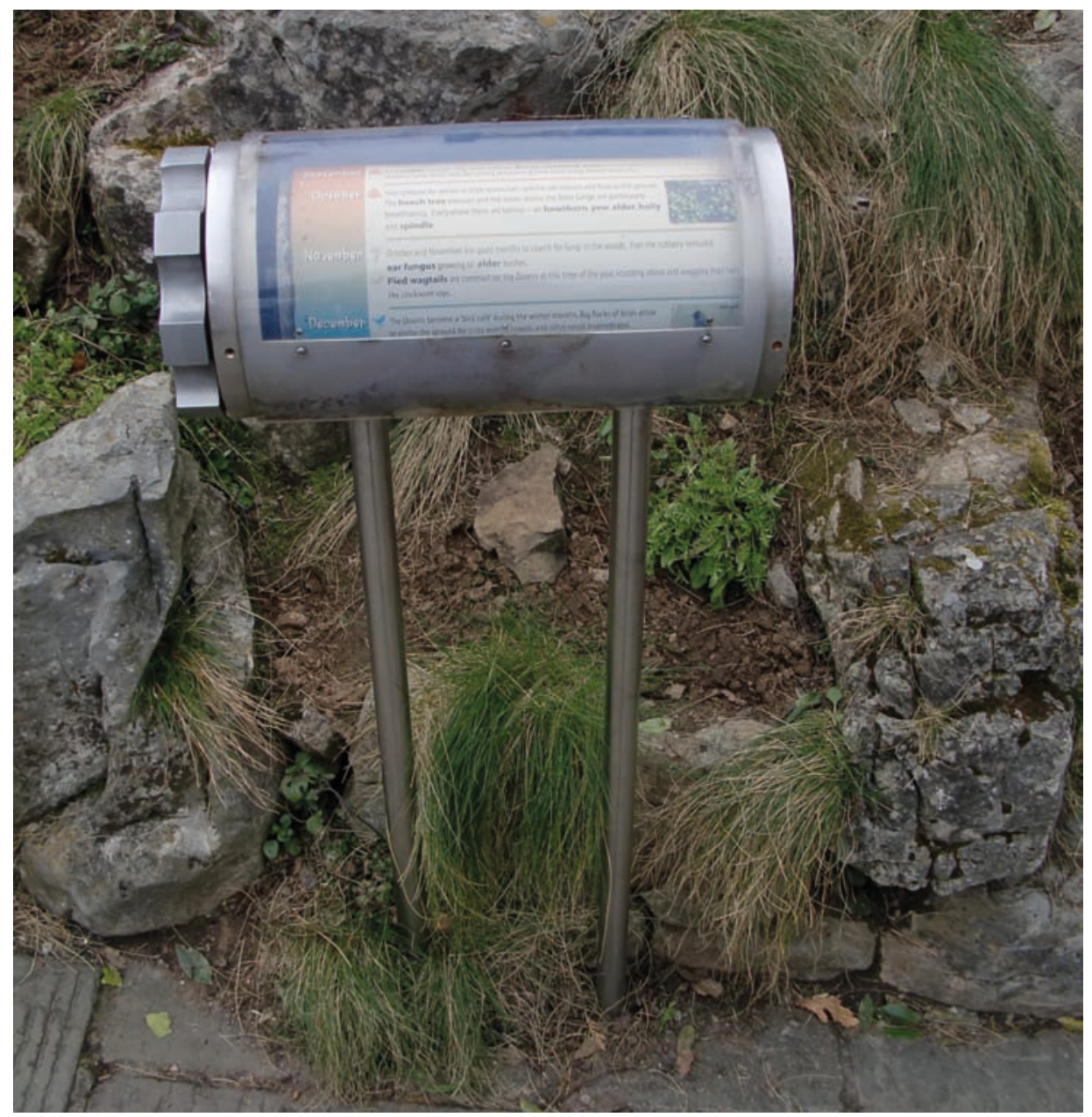

Fig. 7 Interactive calendar at Bristol Zoo. Photo: Katarzyna Goral.

direct their message to a specific audience such as children. To keep visitors' attention and convey the conservation message, panels often used stories or provided a string of interesting botanical and historical facts. This indirect communication aimed not only to inform and explain but to change attitudes and raise the profile and appreciation of the native flora. The survey at Dawyck demonstrated this method to be quite successful: more than half of the respondents thought raising the profile of Scottish plants was the main interpretation message.

Gardens communicated their commitment towards Target 8 and GSPC in a direct way rather than through a story. The survey at Edinburgh showed, however, that when this approach was put into a test the information on GSPC drew little attention. Therefore, it could be worth testing another set of stories such as those on botanistconservationists as today's plant hunters. 
In summary, there is no one correct 'recipe' for an interpretation panel on conservation. The theme, choice of stories, and textual and visual devices depend on the type of visitor targeted, the level of involvement in conservation, the size and type of Target 8 display and many other factors. There are, however, a few points worth considering: one of them is prioritising the main conservation message in the title and first paragraph and illustrating it with an image. Placing panels in a prominent position within the display can secure their visibility. In gardens reaching out to young people more attention could be paid to making the panels tactile and child-friendly. Finally, integrating static and live interpretation so they support each other could strengthen the garden's voice on conservation, but this needs to be tested.

\section{ACKNOWLEDGEMENTS}

My thanks go to Heather McHaffie, Natacha Frachon, Kate Barnard, Vlasta Jamnický, Alan Bennell and Leigh Morris from the Royal Botanic Garden Edinburgh, for giving their help and advice while I worked on my HND Specialist Project. I would also like to thank staff at the Visitor Centre at Dawyck Botanic Garden for their assistance with my survey.

\section{REFERENCES}

BALLANTYNE, R., PACKER, J. \& HUGHES, K. (2008). Environmental awareness, interests and motives of botanic garden visitors: implication for interpretative practice. Tourism Management 29: 439-444.

BENNELL, A., MASPERO, I. \& UNWIN, B. (2003). Logan Botanic Garden. Royal Botanic Garden Edinburgh, Edinburgh.

BGCI (2012). A guide to the GSPC targets. All targets, objectives and facts. Available at: http:// www.plants2020.net/files/Plants2020/popular_guide/englishguide.pdf (Accessed: 28 April 2013).

CBD (2012a). GSPC. Introduction. Available at: http://www.cbd.int/gspc/intro.shtml (Accessed: 28 April 2013).

CBD (2012b). GSPC. Background and consultations. Available at: https://www.cbd.int/gspc/ background.shtml (Accessed: 28 April 2013).

CONNELL, J. (2004). The purest of human pleasures: the characteristics and motivations of garden visitors in Great Britain. Tourism Management 25: 229-247.

FRACHON, N., JEBB, M. \& RAE, D. (2005). PlantNetwork's Target 8 Project - the survey stages. Sibbaldia 3: 67-82.

HAM, S. (1992). Environmental Interpretation. A Practical Guide for People with Big Ideas and Small Budgets. North American Press, Golden, CO.

JOHN FINLAY ASSOCIATES (1998). Wonders at your feet. Scottish rare plants interpretative strategy (draft report for RBGE). John Finlay Associates, Edinburgh.

LEGRAND, P. (2005). The Central Gallery: visitor orientation at the Florida Museum of Natural 
History. MSc dissertation, University of Florida. Available at: http://ufdc.ufl.edu/UFE001176 4/00001/1j?search=streaker (Accessed: 26 April 2013).

MCHAFFIE, H. (2006). Experimental droughting of Woodsia ilvensis (L.) R. Br. Botanical Journal of Scotland 58(1): 71-73.

MCHAFFIE, H. (2011). The Target 8 Project at RBGE. Edinburgh and Lothians Rock Garden Group Newsletter spring 2011: 5-7.

MCHAFFIE, H. (2013). Visit of the ENHS to the Nursery at RBGE on 23.05.2012. The Target 8 Project. Edinburgh Natural History Society Journal 2013: 3-4.

MCHAFFIE, H., FRACHON, N. \& ROBERTSON, A. (2011). Starting a conservation collection of Sorbus pseudomeinichii - the catacol whitebeam. Sibbaldia 9: 171-178.

MONROE, C., LAU, A., SCHUBEL, J. \& CASSANO, E. (2006). The results of a NOAA's National Marine Fisheries Service sponsored workshop. Available at: http://www. aquariumofpacific.org/images/mcri_uploads/OceanLiteracy-WorkshopII.pdf (Accessed: 26 April 2013).

PLANTNETWORK (2013). Target 8 project summary. Available at: http://plantnetwork.org/ plantnetwork-projects/target-8-project-summary (Accessed: 28 April 2013).

PLANTS2020 (n.d). The GSPC targets. Available at: http://www.plants2020.net/gspc-targets/ (Accessed: 28 April 2013).

RBGE (2013). Science and research projects. Available at: http://www.rbge.org.uk/supportus/ donate/appeals-projects/science-and-research-projects (Accessed: 7 June 2013).

RBGE (2014). Honoured for work in Scottish plant conservation. Available at: http://www.rbge. org.uk/about-us/news/stories/honoured-for-work-in-scottish-plant-conservation (Accessed: 2 February 2014).

SHARP, G.W. (1976). Overview of interpretation. In: Sharp, G. (ed.) Interpreting the Environment. John Wiley and Sons, Inc., London.

SHARROCK, S., HIRD, A., KRAMER, A. \& OLDFIELD, S. (2010). Saving plants, saving the planet. Botanic gardens and implementation of GSPC Target 8. Available at: http://www. bgci.org/files/Worldwide/GSPC/target_8_report.pdf (Accessed: 28 April 2013).

TILDEN, F. (1977). Interpreting Our Heritage. University of North Carolina Press, Chapel Hill, NC.

WATERSON, N. \& SAUNDERS, M. (2012). Delightfully lost: A new kind of wayfinding at Kew. Available at: http://www.museumsandtheweb.com/mw2012/papers/delightfully_ lost_a_new_kind_of_wayfinding_at_(Accessed: 26 April 2013).

\section{INTERVIEWS}

BAINES, R. (2013). Interview on 'Local Heroes' beds at Logan (personal interview), RBGE, 25 April 2013.

LUSBY, P. (2013). Interview on Scottish Rare Plant Trail and Scottish Rare Plants Project (personal interview), RBGE, 12 April 2013.

MCHAFFIE, H. (2013). Interview on Scottish Plants Project (personal interview), RBGE, 16 April 2013.

STEWART, G. (2013). Interview on Scottish Rare Plant Trail (personal interview), Dawyck, 18 March 2013.

WRAY, N. (2013). Interview on interpretation at the University of Bristol Botanic Garden (personal interview), Bristol, 27 March 2013. 


\section{APPENDIX 1}

Questionnaire used during the visitor survey at Dawyck Botanic Garden. It was printed on double-sided A4, folded into three and circulated together with Dawyck's visitor map.

\begin{tabular}{|c|c|c|}
\hline $\begin{array}{l}\text { Please, fill in at the end of your visit -- } \\
\text { perhaps, in the café with a nice cup of } \\
\text { coffee. } \\
\text { Q1. What is the main reason for your } \\
\text { visit to the garden? (Tick one box only) } \\
\square \quad \text { To relax. } \\
\square \quad \text { To spend time with family/friends. } \\
\square \quad \text { To walk/exercise. } \\
\square \quad \text { To spent time close to nature. } \\
\square \quad \text { To look at plants. } \\
\square \quad \text { To explore the garden. } \\
\square \quad \text { Other } \\
\\
\\
\text { Q2. Did you notice the Scottish Rare } \\
\text { Plants Trail on your visit? } \\
\square \quad \text { Yes. } \\
\square \text { No (if so, please, go next to Q4). } \\
\text { Q3. What made you aware of the Trail? } \\
\text { (Tick all that apply) } \\
\square \quad \text { I saw information about it on the main } \\
\text { board outside the Visitor Centre. } \\
\square \text { I saw some of its panels while walking } \\
\text { in the garden. } \\
\square \text { I saw a leaflet about the trail at the } \\
\text { front desk in the Visitor Centre. } \\
\square \text { Staff at the Visitor Centre mentioned it. } \\
\square \text { This questionnaire raised my } \\
\text { awareness and made me look for plants } \\
\text { and panels along this trail. } \\
\square \text { Other } \\
\\
\end{array}$ & $\begin{array}{l}\text { Q4. Did you see this panel on your visit? } \\
\square \quad \text { Yes. } \\
\square \text { No. } \\
\square \text { Not sure. } \\
\text { Q5. What do you think about the text on } \\
\text { this panel? - see below. (Tick all that } \\
\text { apply) } \\
\text { Glaucescent Lady's Mantle } \\
\text { Alchemilla glaucescens } \\
\text { Apart from two populations in the } \\
\text { Borders, this rare plant is only found near } \\
\text { cool, northern Ullapool, where it is } \\
\text { threatened by limestone quarrying. It } \\
\text { grows best in fertiliser-free, lightly grazed } \\
\text { grassland and is said to be a traditional } \\
\text { treatment for animal that have been } \\
\text { attacked by elves! }\end{array}$ & $\begin{array}{l}\square \quad \text { It is entertaining. } \\
\square \quad \text { It contains interesting information. } \\
\square \quad \text { It contains a bit too much information. } \\
\square \quad \text { It contains some irrelevant/odd } \\
\text { information. } \\
\square \quad \text { It seems a bit patronising. } \\
\square \quad \text { It is rather boring. } \\
\text { Q6. What do you think is the main } \\
\text { message of this panel? (Tick one box } \\
\text { only) } \\
\square \quad \text { Alchemilla glaucescens is a rare and } \\
\text { little-known treasure of the Scottish } \\
\text { native flora. } \\
\square \quad \text { Alchemilla glaucescens grows only in a } \\
\text { few sites in Scotland and prefers cool } \\
\text { weather, fertilise-free soil and light } \\
\text { grazing. } \\
\square \quad \text { Due to human activity Scottish } \\
\text { populations of Alchemilla glaucescens } \\
\text { are declining. } \\
\square \text { Alchemilla glaucescens has interesting } \\
\text { traditional uses. } \\
\text { Q7. Is there any other information you } \\
\text { would like to see on this panel? (Write } \\
\text { your suggestions below) }\end{array}$ \\
\hline
\end{tabular}

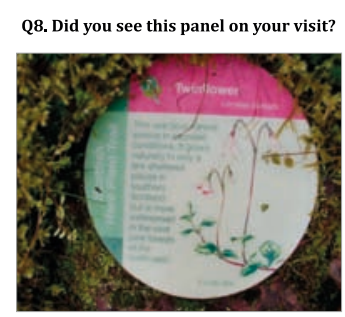

Yes

No.

$\square$ Not sure.

Q9. Can you comment on the layout, style and image on this panel?

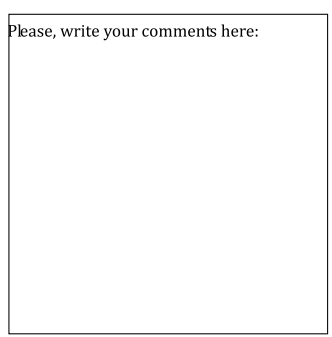

When this picture was taken most of the plants along the trail were dormant. Similarly, on your visit most of the plants were not visible.

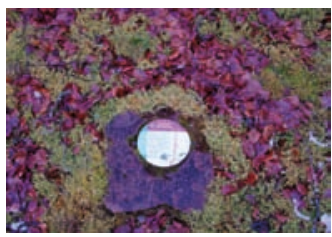

Q10. How interested would you be to see any of the Scottish rare plants when in flower/active growth?

Very interested.

Somehow interested.

Neither interested nor uninterested

Not very interested

Not interested at all

Q11. Do you have any other comments?

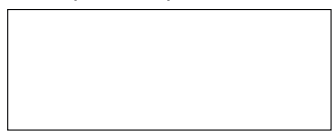

Thank you for your help. Please, return completed questionnaire to the staff at the Visitor Centre.

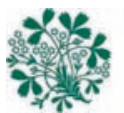

Royal

Botanic Garden Edinburgh

RGBE Student Project Survey

Information Panels

Evaluation

Scottish Rare Plants Trail

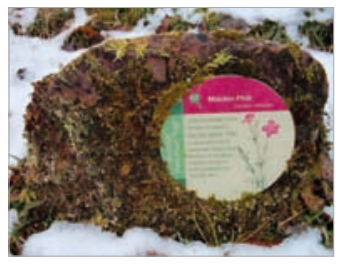

Please, fill in this questionnaire for the panels along the Scottish Rare Plants Trail at the end of your visit to the Garden. 


\section{APPENDIX 2}

List of comments on the visual presentation of panels along the Scottish Rare Plants Trail at Dawyck Botanic Garden.

- Good illustration. Name is obvious on panel and more info there if you want to read.

- Eye-catching and interesting.

- The lovely illustration of this flower has always struck my mind, so that if I ever did see it in the wild I would know what it was instantly.

- Like the artwork, illustration and striking pink band of colour.

- Eye-catching, informative.

- Generally the images and text were of high quality. The colours of the plaques led me to explore areas where I might not have gone and certainly wouldn't have recognised the plants as 'rare'. Moss and lichen encroach on some of the print.

- Identifies the plant. Good balance of image and text. Panel is noticeable but not intrusive. As a frequent visitor I find all the information(?) has been excellent and informative.

- Overall design of the panel provides an instant association with the rare plants theme. The image gives information about the active stage in plant's life not apparent on the date of the visit. That's useful.

- Pink highlights the presence of the panel initially, draws the eye to the flower too.

- Clear.

- Very clear and informative.

- Panel OK.

- Colourful and lovely illustration.

- Attractive and informative. Layout, style and image all seem good.

- Very pleasant and informative.

- Not fond of the colour although I appreciate the need to attract attention.

- Well considered but too small, too low level. Generally too discrete [sic] - too 'precious'.

- Looking a bit dated.

- Picture could be stronger in colour (not easy to see).

- Graphics should be bigger.

- What is the significance of the different colours on the plaques? 